\title{
A Novel Intelligence-based e-Procurement System to offer Maximum Fairness Index in Ongoing Auction Process
}

\author{
N. Madhusudan', L. Manjunatha Rao ${ }^{2}$ \\ ${ }^{1}$ Department of Computer Science, City College, India \\ ${ }^{2}$ Department of Master of Computer Applications, Dr. Ambedkar Institute of Technology, India
}

\begin{tabular}{l}
\hline Article Info \\
\hline Article history: \\
Received Feb 23, 2018 \\
Revised Jul 19, 2018 \\
Accepted Aug 4, 2018 \\
\hline
\end{tabular}

Keyword:

Auction

Bidding

e-Procurement

Optimization

Sales

\begin{abstract}
A perfect auction policy is one of the most strategic elements that contribute to success factor for any e-Procurement system. An auction policy can be only term as an effective if it really offer win-win situation to both the bidder as well as to the merchant. After reviewing existing studies on e-Procurement system, it is found that there isno effective research work focusing on this point and maximum research contribution has limited its scope to certain application or case studis. Hence, the proposed system introduces a novel eProcurement system which is equipped by an itelligence-building process for performing predictive analysis of ongoing auction process. A mathematical modelling is implemented where all teh variables have been formed using practical implementation of auction system and followed by optimization process using regression-based approach. The study outcome shows that proposed system offers better response time and higher predictive accuracy in contrast to existing approaches.
\end{abstract}

Copyright $@ 2018$ Institute of Advanced Engineering and Science. All rights reserved.

\section{Corresponding Author:}

N. Madhusudan, Department of Computer Science. City College, Bangalore, India.

Email: nmadhusudanresearch@gmail.com

\section{INTRODUCTION}

With rapidly growing of web technologies and information and communication techninologies (ICT), the researchers found a easy procurement process for both within and among the organizations, several public institutions and corporations have recognized suitable opportunitied for their benefits and maximizes in efficiency owining to trading websites [1]. However, Electornic-Procurement (e-procurement) is most efficient technology which provides a goods and services thorugh the internet [2], [3]. It is like a supply chain process where suppliers can exchange the services via internet and also as other informantion and networking techniques.

Like e.g. electronic data interchange and enterprise resource planning. Forerunners of e-procurement have been seen in the early 1980'sm with the advancement of planning of material requirement system in resource planning mechanism and later into enterprises resource planning system (ERP) by the middle of 1990's. Additionally, e-data interchange can also be refered as a type of e-procurement [4]. The product purchasing operation and its realted procurement process in the oraganizatios have conventionally been a significant process which affects on performance on business. In several organizations, the total expenditure depends upon procurement costs also. New trends/technologies in the organizational environment suggenst that a significance of procurement is being reinforced via the emergence of universal business supply chains [5].

With the advancement of internet technologies in the organization world, procurers require the time duration to make usage of competative procurement policies for perticular products. Procurers/customers seek lowest costs of good and services, fast buying cycle, short time order processing and miminum 
administrative prices [6], [7]. Conversely, the product suppliers desire advance distribution strategies, a large procurer base, and tries to maximize the sales, minimizes the excess inventory as well as cost of the goods sold. Moreover, both suppliers and custormers seek minimum transactional costs [8]. The usage of eprocuremetn techniques is hoped to provide all these benefits for both parties (i.e. suppliers and procurers) [9]. In universal firm, the decentralized, factored procuring operations have certain way to uniform, the centralized procuring processes, with global procuring decisions being handled by a single centralized organization [10].

These variations may, in part, be attributed to purchasing process which can be decomposed by hierarchical order and the first layer decomposition results four disicts levels such as i) searching and analysis of suppliers, ii) planning and management of product supply chain, iii) supplier section process and iv) electronic transactional process. Several aspects of purchanging, in out of four levels, have profited from ICT application and decision technologies [11], [12]. However, negotiation is the most significant part of the business activities in both physical and electronic market. Compare to automated negotiation a human based negotiation is relatively slower which does not provide the faster severvices. So as to support advance business practices over internet, e-commerce system require the capability to negotiate. Advance interoperability techniques like "open trading protoco" helps to develop a negotiation process during electronic transaction in less or more sophisticated manner and demonstrate the significance of the ecommerce.

Nevertheless, with rapid gowth in the information technologies i.e. advance web technologies, possibilities exists to automate negotiations which occur during the supplier selection process. The development of such automated negotiations needs OR (i.e. operation research) and computer system perspective to feed back in to the negotiation models and the entire process is devised into social scientists and economists [13].

The interdisciplinary research study has contributed into three main approaches to design a automated negotiation systems such approaches are i) designing of negotiation based systems ii) softwareagents for negotiation and iii) develop a auctin based model and online auction platforms. Each approach represents the needs of a variety of negotiatin systems. In this study, have mainly focuses on usage of automated negotiation for e-procurement. The section 1.2 breifly discusses about related work and defines the research problems in the section 1.3. The fundamental concept about e-procurement is discusses in section- 2 followed by significant research gap fro the prior study in section-3. In the last section, have briefly discusses about final conclustion on the proposed study

\subsection{Background}

This section discusses about the existing literatures towards e-procurement system as an extension of our prior work [14]. The work carriedout by Chandrashekar et al. discussed a foundation of e-Procurement system with respect to neogotiation scheme from the engineering approach which permits pragmatic acceptance of economic and social sciences viewpoints over negotiated choices for the reason of sustaining and undertaking electronic discussions [15]. Different theories that cause on-going studies of electronic discussions are recognized in this study along with a foundation for incorporation of various theories and approaches for the precise reason of the design of efficient electronic discussions.

Sundarraj et al. have demonstaretd the characteristics of various kinds of e-procure sales and discussions [16]. They have also extended the conversation to groupings and hybrids of sales and discussions and their probable positions into the e-commerce. Study considering governmental institution of United Kingdom is considered in the study of McConnell et al. [17]. To get better the quality of the task in the sale process, they have built an analytical programming model to choose contract awards optimally among various allowance owners. The model totally changed the nature of the procedure in three crucial features. Intially, it provides intelligibility and objectivity to the full procedure, producing competition amongst firms. Second, it permitted the organisations to construct flexible defensive bids to include their level economies, leading to capable resource allowance.

Sundarraj et al. have studied the optimization principle associated with e-Procurement system [18]. Furthermore, they have shown that an optimization principle approximates fine the normal behavior of advertisers in huge marketplaces. Their second major contribution is to utilise this structure to give sharp instructions for key sale design choices that publishers facade in these marketplaces, such as the preserve cost, the allowance of imitations to the exchange versus an alternative channel, and the disclosure of audiences information. Especially, they establish that suitable alteration of the reserve cost is key in (1) Building benefit table for the publisher to try selling whole imitations in the exchange before using the substitute channel; and (2) Recompensing for the thinner markets produced by greater revelation of audiences information. The work done by Kalianan et al. have presented discussion about e-procurement system in Malaysia where it was demonstrated that the income equivalence rule (that predictable incomes are 
independent of the sale format) holds if the position of acceptable securities is ordered and convex (such as equity) [19]. Or else, it requires not hold. For an example, when bidders give typical debt securities, a second-cost sale is better. Other way, if bidders complete over the exchange proportion of exchangeable liability, an initial-cost sale defers maximum incomes. Lastlly, they have proposed about how various forms of moral chance collision their outcomes.

The study presented by Hazra et al. have presented an e-Procurement strategy that is strategy-proof with esteem to reservation cost, weakly budget-balanced and independently normal [20]. Their device also procedures vendors unlikely to under-report the supply quantity to drive up the market cost. In counting, by leaping their market's effectiveness loss, they offer reasonably unrestrictive sufficient circumstances for the effectiveness of their device to meet in a strong intellect when (a) the no. of agents who successfully deal is huge, or (b) the no. of agents, dealing and not, are huge. The work of Huang et al. discussed the condition of information about intend of combinatorial sales [21]. Next, it utilises this topic as a vehicle to express the features of numeral programming that are applicable for the design of such sales and combinatorial markets in the universal.

The work introduced by same author Nanang et al. discussed about combinatorial sales and brings out significant problesm in the design of combinatorial sales in e-Procurement in association with risk factor [22]. They have also highlighted significant contributions in present research study in this field. Elmaghraby et al (2003) have demonstaretd a review study of the literature and present performance in dynamic costing. Given its applicability in most markets and its growing acceptance in practice, their demonstartation is on active (intertemporal) costing in the occurrence of record deliberations.

The work demonstrated by by same author Nanang et al. discussed about anti-corruption factor of the various selection criteria, the different issues of supplier's selectionand the obtainable techniques to resolve the issue [23]. A numerical example is represented to 1-present the various selection criteria and techniques and 2- to compare the advantages as well as disadvantage of the selection techniques. The study illustrated by Dai and Paracha utilise complicated rounding and local development heuristics to achieve quality results in e-Procurement system of Afghanisthan [24]. They have also represented a test data producer that creates sensible issues and pemits control on the difficulty phase of the issues byusing limitations.

Cabral et al. have proposed a reverse auction system considering case study of Porugal that produces simultaneous manufacture and transportation choices so that the full supply chain price is reduced and makes truthtelling from the trader's [25]. An arithmetical study demonstartes that substantial supply chain price savings may be attained if production and shipping prices are considered concurrently. But, the customer's payments in such sales may be high. After that expand a novel Vickrey kind sale which integrates the customer's reservation cost purpose into quantity distribution and payment decision. As outcomes, the customer has several controls on his payments at the cost of establishing uncertainty in the amount obtained in the sale.

The study done by $\mathrm{Xu}$ et al. has introduced an adaptation of Vickrey, Clarke, Groves (VCG)-based devices in which the managers are given an opportunity to develop the output of the fundamental algorithm [26]. When the managers behave honestly, the benefit attained by the device is at least as good as the one attained by the algorithm's output. They have also presented a strong foundation for truth-telling performance. Their technique satisfies individual rationality also.

This paper studied by Park et al a novel clearing algorithm for multi-unit single-item and multi-unit combinatorial sales with piecewise linear demand/supply purposes [27]. They have also studies the difficulty of their algorithms and establish that they are guaranteed to discover the optimal distribution. Also Giesecke have demonstaretd an approximately-efficient as well as approximately approach proof sale device for a single-good multi-unit allowance issue [28].

The tender language in their sales permits marginal-decreasing piecewise constant arcs. Muller et al. represented a bidding-suggestion tool based over a Myopic Best-Response (MBR) estimation which resolves a connected optimization issue [29]. Ass uming linear costes for the suppliers, they have presented within a game-theoretic structure the series of bids happening in this smart bazar. Under a weak behavioral statement and several symmetry needs, an open upper bound for the winning bids is recognized. Then they have also formulated a complete behavioral model and solution method based on the MBR foundation and demonstarte that the limits derived previous continue to hold. They also logically derive several structural and convergence assets of the MBR dynamics in the easiest nontrivial market surroundings, which suggested further possible design developments, and examine bidding dynamics and incentive compatibility issues via arithmetical models [19].

The study by Li et al. has consideration and formalizes of some bidding process and evaluates their strengths [30]. Chang et al. have proposed a secure and universal language where tenders are given by propositional methods whose subformulae may be explained with costs [31]. This language permits bidder utilities to be invented more naturally and quickly than obtainable languages. Also, they outline a universal 
algorithmic method for winner determination for sales that utilise this bidding language. The work of Fasuga et al. have developed multiattribute e-Procurement methods with configurable offers and devise the bid assessment problem as a linear integer multiple criteria optimization issue [32].

Configurable bids permit multiple standards for every quality and for every cost the bidder may identify cost as a piecewise linear task of the amount. The work of Yen et al. have discussed a transaction process of combinatorial sale which is best for a sensible agent bidding plan, this case myopic very bestresponse bidding [33]. It is optimality established with a new link to primal-dual optimization theory. Hence, there are various studies towards e-procurement system. The next section discusses about the identified research problem.

\subsection{The Problem}

The significant research problems are as follows:

a. Majorty of existing studies has discussed about e-procurement system which is either application specific or case study specific and therefore there is no standard model/framework.

b. There is less number of studies emphasizing on predictive modeling on bidding process which is more demanded for any stakeholders.

c. Existing techniques doesn't discuss about e-Procurement as whole but it just address only developing certain component in e-procurement system and hence less applied on real-time.

d. Majority of the existing techniques are highly feature and application specific with involvement of more number of dependencies towards external agents.

Therefore, the problem statement of the proposed study can be stated as "Developing a novel mathematical model for e-Procurement system to offer accurate response benefitting both bidder and merchancet is computationaly challenging task"

\subsection{The Proposed Solution}

The proposed system aims to develop a framework of bidding system that offers competitive advantage to the consumers in the e-Procurement application. By consumer, it will target for bidder and merchants. As the decision made by bidders as well as merchants are the role players in any e-procement system, the proposed system realizes this importance and incorporates all the essential bidding attributes in its proposed design in order to make predictive computation of the bidding process. The implemented schema of the proposed system is as follows in Figure 1.

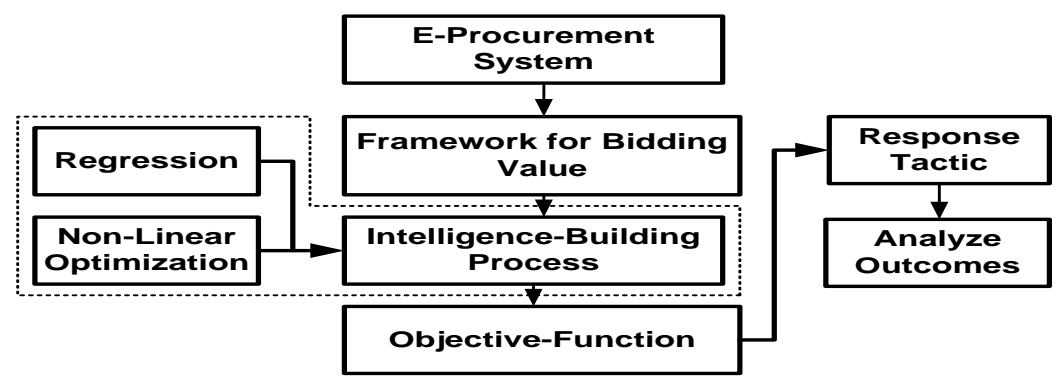

Figure 1. Implemented schema of proposed system

Figure 1 highlights the design principle of proposed e-Procurement system in the form of mathematical modeling. The input to the model is basically the abstract information of the bidding attributes e.g. time of bidding, value of bidding, certain constants for model fine-tuning etc. The first contribution of the proposed model is that it offers a framework that is capable of identifying the bidding value using five significant attributes e.g. minimum and maximum value of bidding, maximum time, rate of concession in bidding process, and constant associated with initial bidding value.

The next part of the model uses statistical regression as well as non-linear optimization principle in order to build an intelligence-building process. A suitable objective function is design for this reason where the intelligence will mean all sorts of bidding information that could offer significant insights to the end result of the bidding i.e. obtaining information about deal-value of ongoing bid process. The proposed model also offers a block for response tactic which is basically responsible to perform the predictive calculation of the final deal-value using time-series analysis. Finally, the study outcome is assessed using computational time and predictive accuracy. The model design is constructed in such a way that it bears higher similarity 
and offers higher reliability when integrated with real-time interface of e-Procurement system. The next section offers description information aboutits implementation strategy.

\section{IMPLEMENTATION}

This section discusses about the implementation technique that ensures to evolve up with an effective outcome in the form of decision making in e-Procurement system. The development of the proposed model is carried out considering the difference scales of bidding values against a set of product or services. The complete process is anticipated to close down within a specific period of time where a specific bidder will be identified with best price for the merchants. Hence, the mathematical design of the proposed model is carried out on the basis of interaction between bidder and the merchant. It was found that there are various significant attributes that affect the bidding process; however, the significant one are i) start bidding value, ii) reserve bidding value, and iii) lifetime of the bidding as shown in Figure 2.

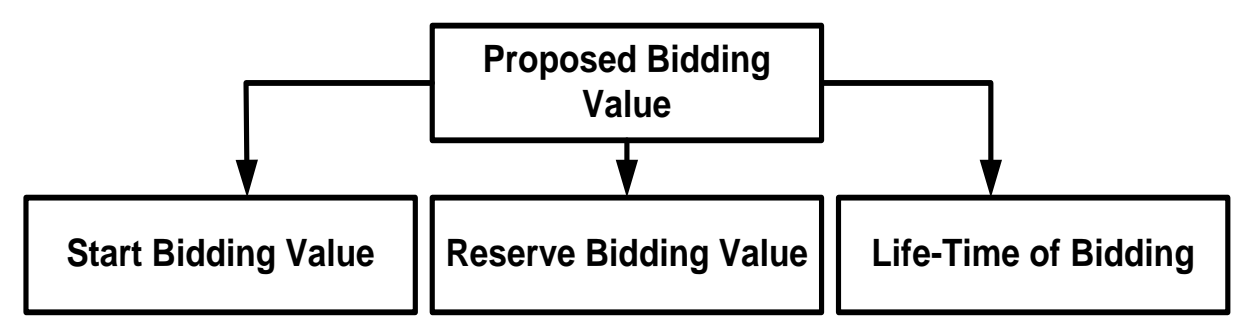

Figure 2. Identified attributes affecting bidding process

The proposed model implements this concept in order to formulate algorithm for problem identification in e-Procurement system. The algorithm takes the input of $\delta$ (offered negotiating value) that after processing yields $f$ (objective function). The steps of the algorithms are as shown below:

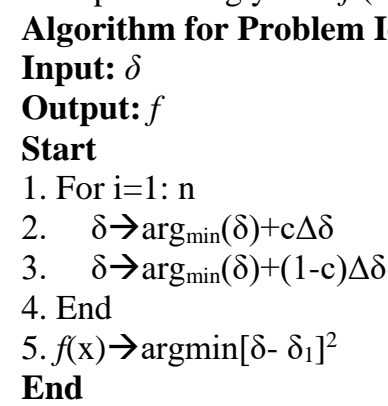

The algorithm considers a variable $n$ that represents total number of bidders and merchants, which will indicate that the above mentioned algorithm will be applicable for all of them (Line-1). Moreover, the iteration of the complete algorithm is anticipated to be equivalent to the frequency of bidding offers where its range is as 0 and $\mathrm{T}_{\max }$. The variable $\delta$ will represent an individual bidding value offered at time instance of $t$ second (Line-2). The first component of the expression will mean that the algorithm selects the minimum bidding offer for a given instance of time $t$. It can be seen that the second component of expression in Line-2 is a product of constant $c$ and $\Delta \delta$ (Line-2). Basically, the constant $\mathrm{c}$ is empirically expressed as,

$$
c=e^{H^{a} \cdot g(m)}
$$

The formulation of constant $c$ is carried out as the proposed algorithm is using time-series analysis process in the process to find out best offer for a given instance of upcoming time. The system also uses a logarithmic function $g(\mathrm{x})$ considering the input argument of $m$ that represents initial bidding value. Hence, the power factor $\mathrm{H}$ is furher expressed by,

$$
\mathrm{H}=1-\operatorname{prob}(\mathrm{t})
$$

The second variable represents a probability of time that is calculated as time instance $t$ divided by maximum time $\mathrm{T}_{\max }$. The power an in expression (1) represents the range of $\mathrm{H}$. It should be understood that 
the proposed algorithm uses mathematical expression shown in Line-2 and Line-3 for representing bidding value of bidder and merchant respective for a specific instance of time $t$. In this algorithm, the role of variable $a$ depends on specific rate of concession that is found for the bidding price to the reservation price by the bidder. Hence, the convergence of the algorithm is dependent on it. Therefore, Line- 1 to Line- 4 represents a mathematical model for managing offers generated during bidding process in e-procurement system. The next part of the implementation is to induce non-linear regression approach on the bidding attributes in order to incorporate intelligence system to the e-Procurement system. For this purpose, an offset variable $\rho$ is used that is mathematically represented as,

$$
\rho=\left\{\arg _{\min }(\delta), \arg _{\max }(\delta), \mathrm{a}, \mathrm{m}\right\}
$$

A closer look into expression (3) shows that $\rho$ represents bidding attributes and therefore the estimated value of the bidding attributes can be mathematically represented as,

$$
\rho_{1}=\left\{\arg _{\min }\left(\delta_{1}\right), \arg _{\max }\left(\delta_{1}\right), \mathrm{a}_{1}, \mathrm{~m}_{1}\right\}
$$

The above expression assists in formulating the offered price of bidding in e-procurement system where updated bidding price and its respective value can be represented as $\delta=\mathrm{g}[\rho]^{\mathrm{T}}$ and $\delta_{1}=\mathrm{g}\left[\rho_{I}\right]^{\mathrm{T}}$. Therefore, the system computes the factor that affects building the intelligence system in the form of an objective function expressed in Line-5. This mathematical expression shows that proposed system applies statistical approach of regression analysis using non-linear optimization principle for ensuring that there is no overhead in obtaining difference in prior and updated bidding price that directly contributes to reduce computational complexity and results in faster generation of outcome. Hence, a least squares are computes for $\delta$ and $\delta_{1}$ as a part of regression analysis with an objective function to minimize such errors.

The optimization of the proposed algorithm follows: -After obtaining the true bidding value, it is considered as initial point which is than subjected to a process of minimizing the squared values obtained. For this purpose, a Taylor series is applied over the initial point. Depending upon the linearity of the distribution of points (representing different bidding values), the process of updating is carried out on bidding attribute $\rho$. Finally process of approximation is further improved using $\rho_{1} i$.e. new updated value of bidding. The next process of optimization is carried out using intelligence-building mechanism by using a coefficient computed by product of a constant and identity matrix. The fine-tuning of the constant is carried out in order to further minimize the errors in the outcome.

After the above mentioned process of identification of the problem associated with bidding attribute is over, the next step is to offer response against the ongoing or completed bidding process in order to exhibit the information about the e-procurement system. The development of the response tactics is carried out on the basis of i) identification of specific range, 2) practicality assessment, and 3) finetuning bidding attributes as shown in Figure 3.

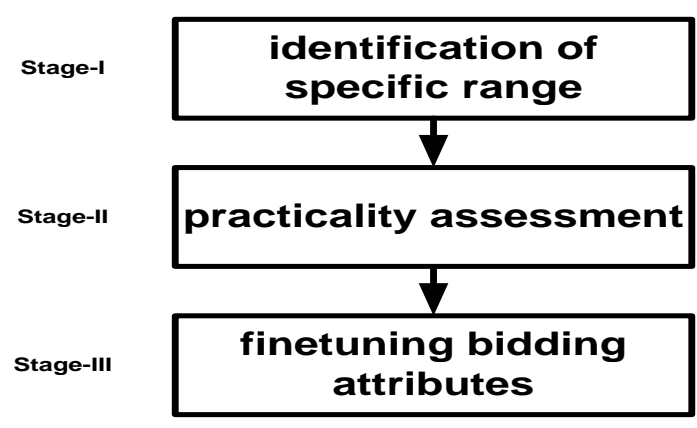

Figure 3. Constructing response tactics in e-proceurement system

This can be realized if it is assumed that there is a dealing point found at M-point during the bidding system in e-Procurement. In the initial state of identification of specific range, the emphasis is mainly to check if there is any feasibility to obtain enhanced performance for the given state of bidding attributes. Once the specific range is identified and chosen, the consecutive process will be to evaluate the reduced bidding price that could be highly practical. The study considers that a strong bidding price can be practical if it is found minimal than any bidding reserve price as well as it should be also more than ongoing bidding price. 
Another constraint to be satisfied will be that number of bidding turn should be minimal than bidding maximum time $\mathrm{T}_{\max }$ in order to show his reliability score in process of bidding.

Ultimately, in last stage, the rate of concession is finetuned in order to obtain a better score of bidding price. A closer look into the proposed algorithm design shows that the design principle retains complete real-world problem associated with the e-Procurement system so that prices offered during bidding system is represented as fair score for both the bidder and the merchant. Therefore, the proposed algorithm is anticipated to be executed on any e-procement system by direct connection with the historical database as well as by capturing the dynamic information during the ongoing bidding process. Another contribution of the proposed system is that it also offer a significant form of cost effective solution in terms of intelligence building tactics without any form of dependencies on exernal software or hardware elements.

\section{RESULT ANALYSIS}

This section discusses about the outcomes obtained from the proposed study. The complete mathematical model discussed in prior section has been scripted using MATLAB. In the entire process of result analysis, emphasize was offered on evaluating the computational time as well as accuracy associated with the bidding process in e-Procurement system. For an enhance form of result analysis, the outcomes have been compared with some of the existing approaches of e-Procurement system e.g. Dai et al. [24], Fu et al. [34], Idress et al. [35]. The outcomes of comparative analysis are as shown in Figure 4.

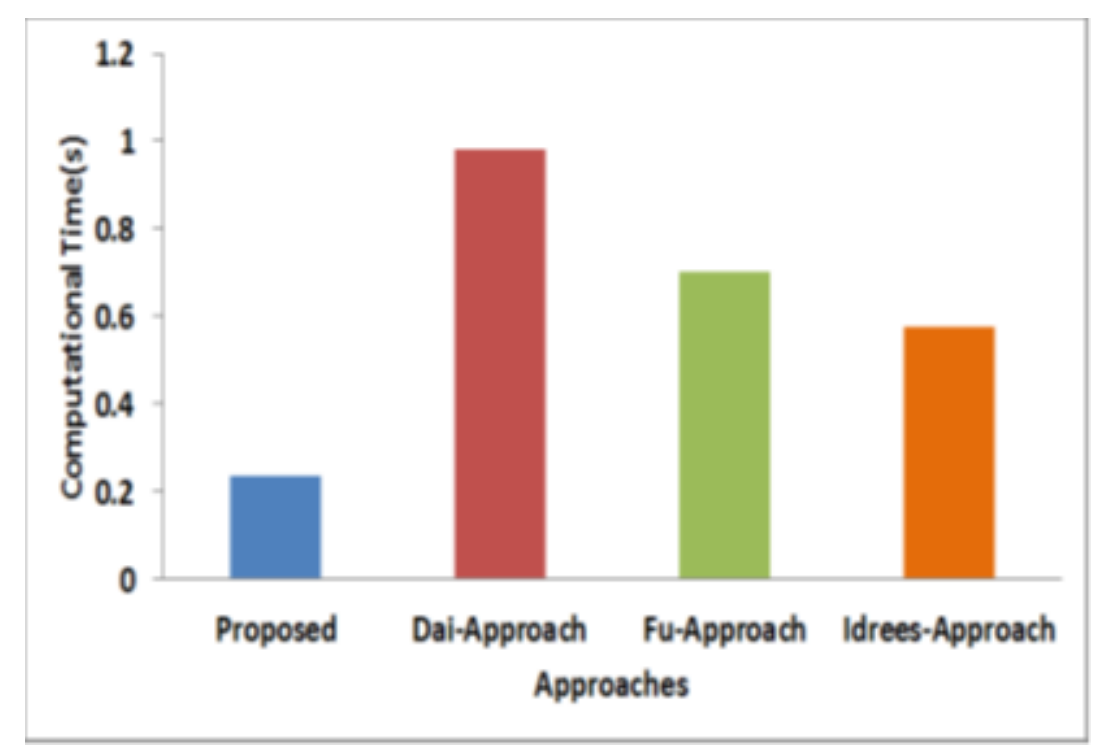

Figure 4. Comparative analysis of computational time

Figure.4 highlights that proposed system offers improvement of computational time by $74.89 \%$, 46.82\%, 34.28\% compared to Dai et al. [24], Fu et al. [34], Idress et al. [35] respectively. The prime reason behind this is none of these existing systems were found to adopt the time-based optimization process for which reason there is an involvement of significant computational time. Moreover, existing system is more application specific which has its own dependencies on external agents, whereas no such things have been considered in proposed system. Hence, the proposed system offers faster response time for catering up faster bidding demands on e-procurement system.

Figure 5 highlights that accuracy of computing the bidding attribute for proposed system is better by 15.55\%, 19.52\%, and 8.08\% in comparison to Dai et al. [24], Fu et al. [34], Idress et al. [35]. The prime reason behind this is proposed system computes well-defined uncertainties using non-linear optimization mechanism using regression. This mechanism consistently computes the least square errors and performing minimization according to the goal of defined objective function. Hence, irrespect of any condition, the proposed system offers well defined analysis of ongoing bidding system that offers competitive benefits for both bidders as well as merchant in e-Procurement system. 


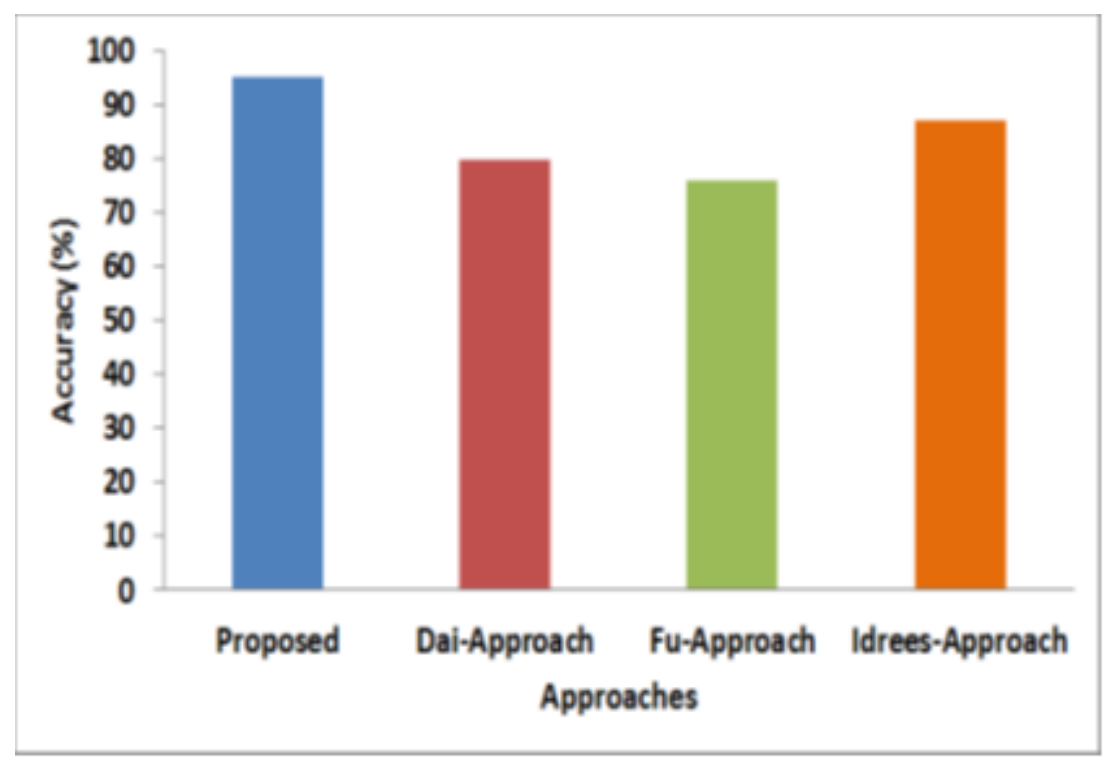

Figure 5. Comparative analysis of bidding accuracy

\section{CONCLUSION}

Auction is one of the essential backbones of any e-Procurement application irrespective of any product or services. Usually, operations of such services are left on to mercy of either user's skill or smart software program. Untill now, usage of so called smart software programes are less found in literature and more emphasis was given to application development to address specific set of problem. However, the primary contribution of proposed study is that it offers a generalized e-Procurement model that can be used for any field of e-procurement and hence it is highly cost-effective from its design viewpoint. The second contribution is the intelligence system that offers enhanced capability to compute the predictive parameters of bidding attributes with respect to time. Hence, the outcome becomes more measurable and more practical. The third contribution is that proposed outcome shows better accuracy at reduced operation time, which is not seen in any existing models.

\section{REFERENCES}

[1] F.Therin, "Handbook of Research on Techno-Entrepreneurship, Second Edition: How Technology and Entrepreneurship are Shaping the Development of Industries and Companies", Edward Elgar Publishing, pp. 400, 2014

[2] H. Bidgoli, "The Handbook of Technology Management, Supply Chain Management, Marketing and Advertising, and Global Management", John Wiley \& Sons, pp. 931, 2010

[3] N. Rienhuber, "Current Adoption and Future Prospects of Electronic Reverse Auctions in the Austrian Automotive Industry", GRIN Verlag, pp. 78, 2011

[4] M. Röthlin, "Management of Data Quality in Enterprise Resource Planning Systems", BoD - Books on Demand, pp. 304, 2010

[5] M.H. Hugos, "Essentials of Supply Chain Management", John Wiley \& Sons, pp. 368, 2018

[6] Diabagate, Amadou, Abdellah Azmani, and Mohamed El Harzli. "Selection of the Best Proposal using FAHP: Case of Procurement of IT Master Plan's Realization." International Journal of Electrical and Computer Engineering 7.1 (2017): 353 .

[7] Mohanty, Suneeta, Prasant Kumar Pattnaik, and G. B. Mund. "Privacy Preserving Auction Based Virtual Machine Instances Allocation Scheme for Cloud Computing Environment." International Journal of Electrical and Computer Engineering (IJECE) 7.5 (2017): 2645-2650.

[8] Setyono, Andik, and Siti Nur Aeni. "Development of Decision Support System for Ordering Goods using Fuzzy Tsukamoto." International Journal of Electrical and Computer Engineering (IJECE) 8.2 (2018): 1182-1193.

[9] D. Lowe, "Commercial Management: Theory and Practice", John Wiley \& Sons, pp. 528, 2013

[10] E. Qi, J. Shen, R. Dou, "Books on Google Play Proceedings of 2013 4th International Asia Conference on Industrial Engineering and Management Innovation (IEMI2013)", Springer Science \& Business Media, pp. 1082, 2014

[11] "Decision Management: Concepts, Methodologies, Tools, and Applications: Concepts, Methodologies, Tools, and Applications, Volume 1", Management Association, Information Resources, IGI Global, pp. 2314, 2017

[12] T-h. Kim, J. Ma, W-c. Fang, Y. Zhang, A. Cuzzocrea, "Books on Google Play Computer Applications for Database, Education and Ubiquitous Computing: International Conferences, EL, DTA and UNESST 2012, Held as Part of the 
Future Generation Information Technology Conference, FGIT 2012, Gangneug, Korea, December 16-19, 2012. Proceedings", Springer, pp. 356, 2012

[13] M. Warkentin, "Trends and Research in the Decision Sciences: Best Papers from the 2014 Annual Conference", FT Press, pp. 400, 2014

[14] N. Madhusudan, L. Manjunatha Rao, "Insights on Extent of Effectiveness, Trend, and Gap in Existing Frameworks for e-Procurement System", International Journal of Electrical and Computer Engineering, Vol. 6, No. 2, pp. 751758, 2016

[15] T. S. Chandrashekar, Y. Narahari, C. H. Rosa, D. M. Kulkarni, J. D. Tew and P. Dayama, "Auction-Based Mechanisms for Electronic Procurement," in IEEE Transactions on Automation Science and Engineering, vol. 4, no. 3, pp. 297-321, July 2007.

[16] R. P. Sundarraj and W. W. H. Mok, "Models for Human Negotiation Elements: Validation and Implications for Electronic Procurement," IEEE Transactions on Engineering Management, vol. 58, no. 3, pp. 412-430, Aug. 2011.

[17] D. J. McConnell, N. F. Doherty and F. Ellis-chadwick, "Exploring the uptake and application of electronic procurement to central and local government," 2010 Fourth International Conference on Research Challenges in Information Science (RCIS), Nice, France, 2010, pp. 453-462.

[18] R. P. Sundarraj and X. Shi, "Optimization-Based Methods for Improving the Accuracy and Outcome of Learning in Electronic Procurement Negotiations," in IEEE Transactions on Engineering Management, vol. 59, no. 4, pp. 666678, Nov. 2012.

[19] M. Kaliannan, S. D. Chandran and R. Hashim, "Electronic procurement implementation in Malaysia: Suppliers' readiness," 2010 International Conference on Science and Social Research (CSSR 2010), Kuala Lumpur, Malaysia, 2010, pp. 1334-1339.

[20] J. Hazra and B. Mahadevan, "A procurement model in an electronic market with coordination costs," 2011 IEEE International Conference on Industrial Engineering and Engineering Management, Singapore, 2011, pp. 1364-1368.

[21] M. Huang and X. Qian, "FAHP-BOCR Based Framework for Single Item Multi-attribute Procurement in B2B Electronic Reverse Auctions," 2011 Fourth International Joint Conference on Computational Sciences and Optimization, Yunnan, 2011, pp. 1201-1205.

[22] H. Nanang, A. F. Misman and Z. Zulkifli, "Trust, risk and public key infrastructure model on e-procurement adoption," 2017 5th International Conference on Cyber and IT Service Management (CITSM), Denpasar, 2017, pp. $1-6$.

[23] H. Nanang and A. F. Misman, "Certificate-Based Strategy to Auction Model for E-Procurement in Indonesia: A Review on Local Ethics and the Future Challenges," 2016 6th International Conference on Information and Communication Technology for the Muslim World (ICT4M), Jakarta, 2016, pp. 41-46.

[24] A. S. Dai and S. Paracha, "Bringing effectiveness, efficiency and transparency in project management through a robust e-procurement system in Afghanistan," 2016 International Conference on Applied System Innovation (ICASI), Okinawa, 2016, pp.1-4.

[25] Ó. Cabral, L. Ferreira and G. P. Dias, "Adoption of reverse auctions in public e-procurement: The case of Portugal," 2016 11th Iberian Conference on Information Systems and Technologies (CISTI), Las Palmas, 2016, pp. 1-5.

[26] S. X. Xu, S. Li, M. Zhang and G. Q. Huang, "Optimal auctions for transportation service procurement in an infinite horizon inventory system," Proceedings of the 11th IEEE International Conference on Networking, Sensing and Control, Miami, FL, 2014, pp. 13-18.

[27] Y. Park, P. Hong, R. Sugie and S. K. Callaway, "Dynamic network innovation in emerging markets: From supply chain to demand chain," Proceedings of PICMET '14 Conference: Portland International Center for Management of Engineering and Technology; Infrastructure and Service Integration, Kanazawa, 2014, pp. 764-770.

[28] R. Giesecke, "The electric mobility business ecosystem," 2014 Ninth International Conference on Ecological Vehicles and Renewable Energies (EVER), Monte-Carlo, 2014, pp. 1-13.

[29] M. B. Müller, M. T. P. Adam, D. J. Cornforth, R. Chiong, J. Krämer and C. Weinhardt, "Selecting Physiological Features for Predicting Bidding Behavior in Electronic Auctions," 2016 49th Hawaii International Conference on System Sciences (HICSS), Koloa, HI, 2016, pp. 396-405.

[30] S. Li, X. Li, M. X. He, S. K. Zeng and X. L. Tang, "Sealed-BID electronic auction without the third party," 2014 11th International Computer Conference on Wavelet Actiev Media Technology and Information Processing (ICCWAMTIP), Chengdu, 2014, pp. 336-339.

[31] C. C. Chang, T. F. Cheng and W. Y. Chen, "A Novel Electronic English Auction System with a Secure On-Shelf Mechanism," in IEEE Transactions on Information Forensics and Security, vol. 8, no. 4, pp. 657-668, April 2013.

[32] R. Fasuga, G. Toporkova and M. Paluch, "Advanced Market Trends Analysis in Electronic Auction Systems," 2011 UKSim 5th European Symposium on Computer Modeling and Simulation, Madrid, 2011, pp. 231-236.

[33] C. T. Yen, T. C. Wu, M. H. Guo, C. K. Yang and H. C. Chao, "Digital product transaction mechanism for electronic auction environment," in IET Information Security, vol. 4, no. 4, pp. 248-257, December 2010.

[34] H-P. Fu, T-H. Chang \& W-H. Wu, "An implementation model of an e-Procurement system for auto parts: a case study", Production Planning \& Control: The Management of Operations, Vol. 15, No. 7, PP. 662-670, 2004

[35] A. M. Idrees, "Towards an automated evaluation approach for e-procurement," 2015 13th International Conference on ICT and Knowledge Engineering (ICT \& Knowledge Engineering 2015), Bangkok, 2015, pp. 67-71. 


\section{BIOGRAPHIES OF AUTHORS}

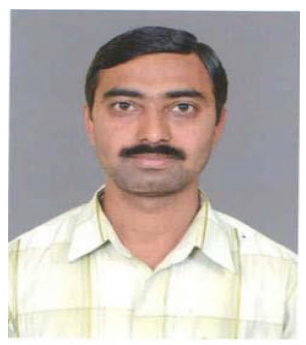

Mr. N. Madhusudan has done Master of Computer Application from Mysore University, India in 1995. He has worked in various reputed Educational Institutions. He has total of 17 years of strong experience in Educational field. Currently he is pursuing his Ph.D from Bharathiar University, Coimbatore, India.

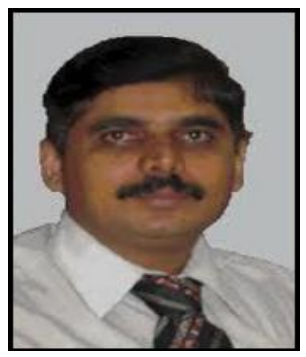

Dr. L. Manjunatha Rao is working as Professor and Head, Department of MCA, Dr.AIT, Bangalore. He has got 25 years of teaching experience. He did his Bachelor of Science from Bangalore University in the year 1990. He Studied Masters of Computer Application from Madhurai Kamaraj University and was awarded in the year 1999. In 2002 did Master of Philosophy from Mononmanium Sundaranar University. He has awarded Ph.D from Vinayaka Mission University, Tamil Nadu. He has published research papers in both national and international Journals and has authored 2 textbooks. 